\title{
REFLEXIONES SOBRE LA PRESENCIA DE LA MUJER EN LA MÚSICA CLÁSICA EN EL PERÚ
}

\section{REFLECTIONS ON THE PRESENCE OF WOMEN IN CLASSICAL MUSIC IN PERU}

\author{
Mina Maggiolo Dibos \\ Universidad Nacional Mayor de San Marcos \\ Lima, Perú \\ https: / / orcid.org/0000-0002-1452-4660 \\ minamaggiolo@hotmail.com
}

\section{Resumen}

Partiendo como uno de los principales canales de la primitiva comunicación humana, la música ha estado desde siempre ligada a la existencia del hombre.

En este artículo, intentaremos realizar algunas reflexiones donde podamos seguir, de manera general, cómo la mujer se relaciona con la música en una línea de tiempo a través de la historia, de acuerdo a un progresivo protagonismo de la misma en el espacio público.

Finalmente, nombraremos algunas de las representantes femeninas destacadas en el ámbito musical del Perú durante el período comprendido entre los siglos XX y XXI.

Palabras clave: historia, mujer, música.

\section{Abstract}

Starting as one of the main channels of primitive human communication, music has always been linked to the existence of man.

In this article, we will try to make some reflections where we can follow, in a general way, how women relate to music in a timeline through history, according to its progressive prominence in public space.

Finally, we will name some of the outstanding female representatives in the musical field of Peru during the period between the 20th and 21st centuries.

Keywords: history, women, music. 


\section{LA DIMENSIÓN MUSICAL}

Siendo la música una expresión artística que tiene como dimensión el tiempo, a diferencia de otras expresiones como la arquitectura, la pintura y la escultura, cuya dimensión está constituida, además del tiempo, por el espacio.

La música posee un carácter singular de inmaterialidad que permite que la relación entre el producto estético que nos brindan el o los intérpretes ingrese a nuestro interior sensible a través del oído, tocando las fibras de nuestra emoción. Esta característica particular y el hecho de tener solamente al tiempo como dimensión, es una de las razones por las cuales, muchas veces, ocurre un desfase temporal con el resto de expresiones artísticas.

El hecho de no constituirse como algo "tangible", también tiene que ver con la relación que algunas veces tiene con el ser humano y que se manifiesta como algo mágico e inalcanzable para aquellas personas que no tienen una formación musical.

Por otro lado, existe una especie de admiración por individuos que pueden leer o escuchar de manera interna los "jeroglíficos" que, para muchas personas, representa la escritura sobre el pentagrama, creándose también, de este modo, una relación mágica no sólo con la música, sino con el intérprete, capacitado para leer e interpretar las composiciones y llevar al oyente las obras de los grandes maestros.

La naturaleza de la música de las culturas antiguas la deducimos por los vestigios de representaciones iconográficas de los músicos y de sus instrumentos en las pinturas, esculturas, relieves y cerámicas de los restos arqueológicos, así como a partir de la escritura incipiente de signos que, de alguna manera, denotaron en la cultura griega la altura de los sonidos. (Sach,1981).

Al no existir un registro que nos brinde un testimonio real de la manera cómo las culturas antiguas occidentales, orientales y americanas concibieron e interpretaron la música en sus días, es imposible conocer su exacta sonoridad. Mientras que, paralelamente, otras muestras de su cultura, como monumentos, construcciones, esculturas, cerámicas, telares y piezas de orfebrería sí podemos percibirlas y apreciarlas de manera visual y tangible. (Arróspide de la Flor, 2000).

Lo que está claro es que el carácter mágico atribuido al arte musical, aludido líneas atrás, se da en todas las civilizaciones antiguas. (Hauser,1969). 
La música estuvo unida a la danza, a la poesía, al culto de los dioses y relacionada a necesidades que el hombre pudo haber tenido, como es el caso de la lluvia o el apaciguamiento de los fenómenos naturales. ${ }^{1}$ (Fubini,1989)

\section{LA RELACIÓN DE LA MUJER CON LA MÚSICA EN EL TIEMPO}

Podemos inferir que la mujer está muy unida desde sus inicios al arte musical por el hecho mágico e inexplicable de la maternidad. Al igual que el ser humano pide por la lluvia o el sol, lo más probable es que, al intentar comunicarse con los dioses, haya implorado con danzas y cantos por nacimientos de niños saludables en los momentos de alumbramiento, así como en todos los acontecimientos importantes de la vida del hombre.

Con el tiempo, la mujer fue siendo relegada al espacio privado del hogar, a la crianza de los niños, siendo el hombre el proveedor del sustento del hogar y destinado a una presencia dominante en el espacio público. Esto mantuvo a la mujer apartada de los acontecimientos sociales y, con excepciones, se le vio destacar activamente en ellos.

Así, nos recuerda Perrot (2009, p.20):

El relato de la historia tal como lo construyen los primeros historiadores griegos o romanos concierne al espacio público: las guerras, los reinados, los hombres "ilustres", o al menos los hombres públicos. Lo mismo sucede con las crónicas medievales y la historia sagrada, que habla de santos más que de santas. Y además, los santos actúan, evangelizan, viajan. Las mujeres preservan su virginidad y rezan. $\mathrm{O}$ acceden a la gloria por el martirio, espléndido honor. (Perrot, 2009, p. 20)

En el medioevo, la expresión musical por excelencia, el canto gregoriano, fue interpretado por monjes, la música de la aristocracia secular por trovadores y la música popular por juglares, siempre hombres que cantaban a sus damas proclamándoles su amor o, a las hazañas de los héroes.

La mujer siempre constituyó una suerte de "musa", de inspiración de literatos, poetas, escultores, pintores y músicos. Tuvo el rol pasivo de un

1 En las culturas antiguas, fue común encontrar vestigios donde el hombre danza, y toca instrumentos. En el Perú, vemos representaciones en la cerámica Moche. (Bolaños, 1998.p.22) 
"ser inspirador". También ejecutó instrumentos, pero siempre en el ámbito privado del hogar. Sería muy interesante investigar en qué momento la mujer deja el rol pasivo de musa de los artistas para convertirse en creadora de su propia obra. Sin duda, este tránsito debió haberse dado, de manera paulatina, en el tiempo.

Las mujeres estuvieron prohibidas de participar en la escena de los teatros por mucho tiempo, siendo representadas por hombres disfrazados de ellas. Aquellas mujeres que osaban interpretar papeles teatrales eran estigmatizadas como mujeres de vida ligera. Las mujeres compositoras y escritoras desarrollaron su arte dentro de sus hogares y usaron seudónimos masculinos para que sus obras fueran leídas o escuchadas, como es el caso de la escritora francesa Amandine Aurora Dupin, conocida por el público como George Sand.

A partir del siglo XIX, la mujer empieza a tomar conciencia de la importancia de usar su propio nombre y de aparecer, poco a poco, en la escena con su propia identidad. Un ejemplo importante de una compositora del período romántico, ya en el siglo XIX, es Clara Wieck, conocida como Clara Schumann, gran pianista y compositora, casada con el compositor alemán Robert Schumann. Así, Clara Wieck viajó por muchos lugares de Europa llevando su arte, convirtiéndose en una de las mujeres emblemáticas de su tiempo, como difusora e intérprete de la música a nivel internacional. (Samuel, 2007).

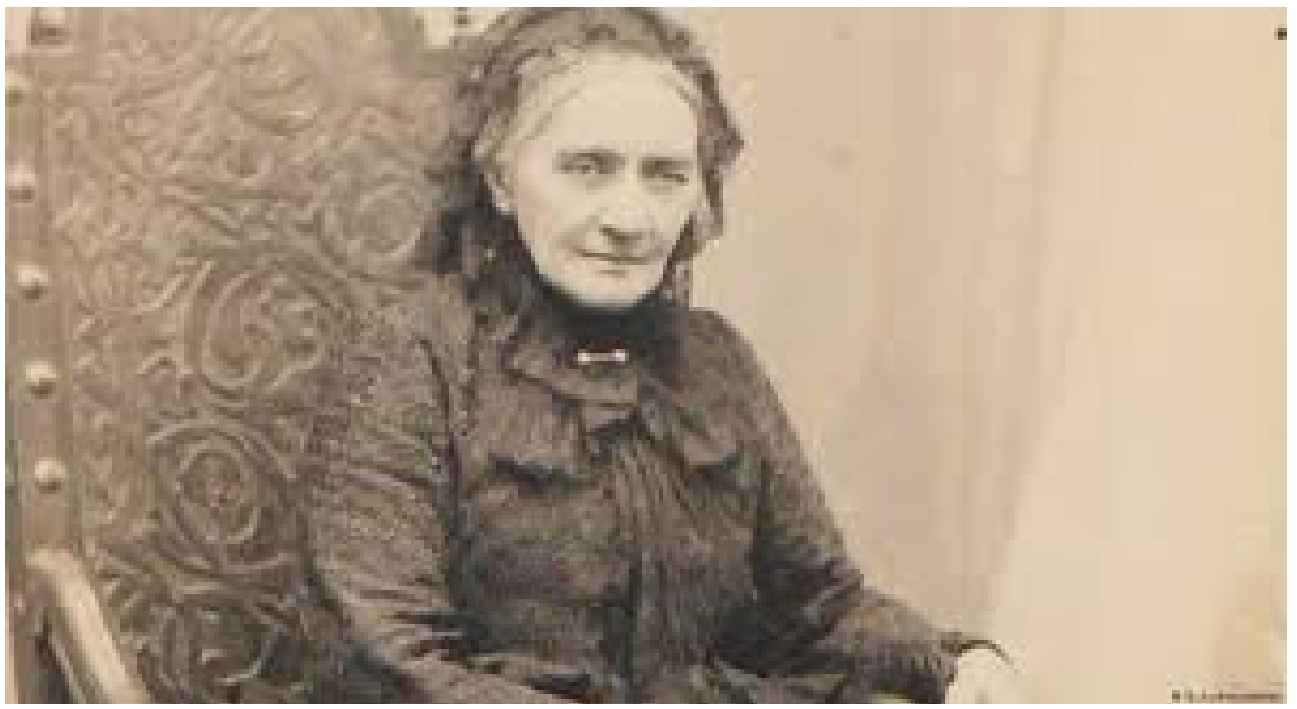

Figura 1. Clara Wieck de Schumann. [fotografía] https://www.dw.com/es/claraschumann-artista-y-supermujer-del-siglo-xix/a-50425190 


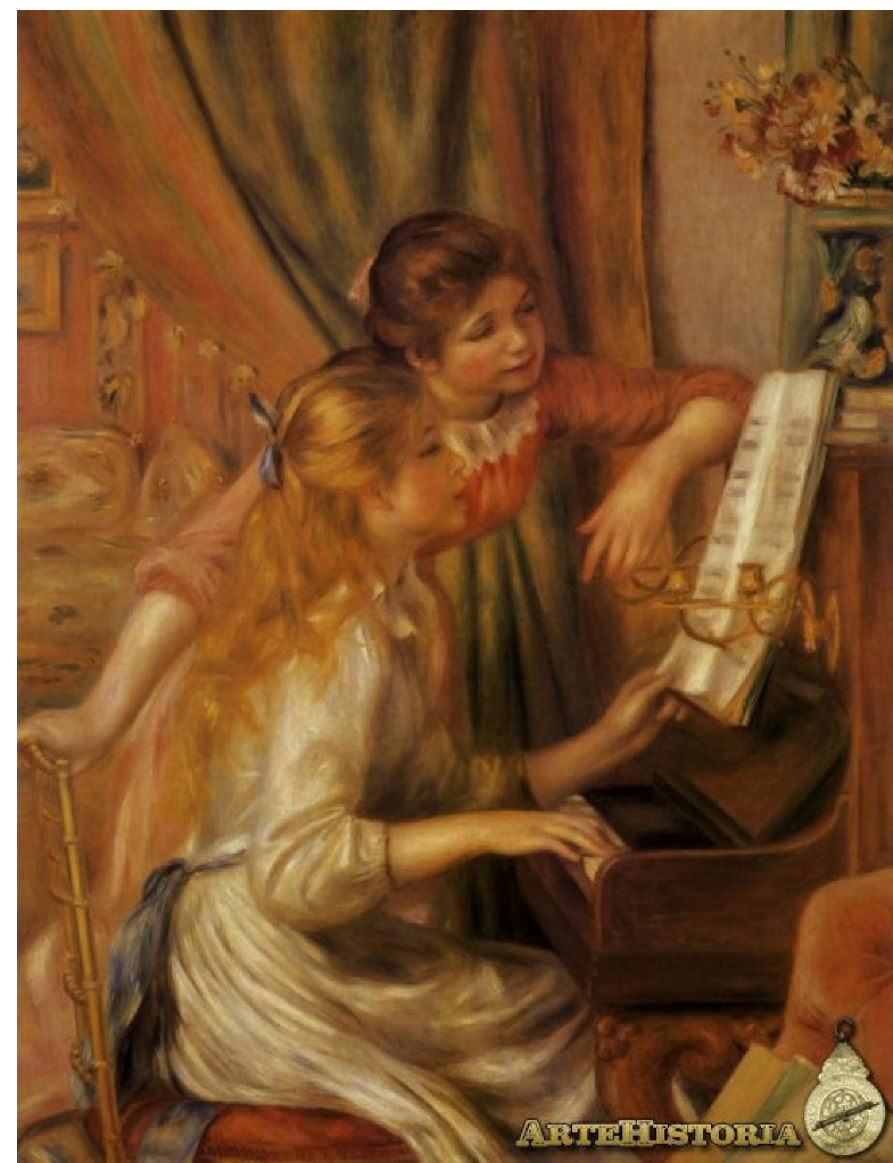

Figura 2. Niñas al piano. Pierre August Renoir. [fotografía] https://es.wahooart.com/@@/9H5SBJ-Pierre-AugusteRenoir-Juenes-filles-au-piano-de-(-las-ni\%C3\%B1asen-el-piano-)-

Ha sido una conquista larga, dura y con mucho por delante para llegar a la igualdad de oportunidades en los ámbitos artístico y profesional, en general. Sin embargo, este esfuerzo nos lleva a meditar sobre la necesidad de alcanzar la excelencia profesional, que es lo único que debe de primar en la formación de un buen artista.

Nuestro enfoque es que las mujeres, por su práctica ancestral con la crianza de los niños y la fortaleza que exige su rol en la maternidad, se ha acostumbrado a luchar con más fuerza por lograr sus metas en la vida. Esto sumado a una relegación, desde siempre convertida en natural y aceptada por ellas mismas como tal, que ocurre, en unas más que en otras, en diferentes sociedades de la actualidad. 


\section{LA MUJER Y LA MÚSICA EN EL PERÚ CONTEMPORÁNEO}

En el Perú, al igual que en otros países del mundo, la conquista de las mujeres por interpretar en público, o, en el caso de las compositoras, hacer escuchar sus obras, también ha constituido algo aún pendiente de consolidar, que sólo con la capacidad y la seriedad profesional de cada una de ellas, ha sido la bandera enarbolada para convencer de sus cualidades al gran público y a los propios músicos varones.

Cuando un músico, hombre o mujer, tiene talento y lo demuestra al componer, tocar algún instrumento, interpretar alguna pieza, o dirigir una orquesta, de inmediato es reconocido por aquellos que comparten la misma disciplina. Es así como nuestro país cuenta con una larga lista de mujeres destacadas en el campo de la música académica.

En el campo de la composición, existen representantes como Olga Pozzi-Scot (n.1933), con destacada labor como docente y con numerosas obras compuestas, de corte vanguardista, como: La Missa Triste, Mirabilis I y II, Jubilation N.2, y su concierto para violín. Asimismo, Isabel Turón, única compositora de la generación del 70. Por su parte, Consuelo Levi Stubbs compuso hermosas obras para piano de estilo romántico.

Por otro lado, tenemos a Rosa Alarco, compositora, investigadora, arreglista y musicóloga. Fue fundadora del Coro de la Universidad Nacional Mayor de San Marcos, ganando el premio "Casa de las Américas" por su investigación sobre el compositor peruano Alfonso de Silva. Ania Paz, es una compositora y pianista especializada en jazz, egresada de la Hochschule für Musik Detmold, Alemania y de una permanente actividad musical en Perú, Puerto Rico y Alemania.

Dentro del campo de las intérpretes, tenemos a la solista de piano Teresa Quesada, una de las más destacadas del siglo XX. Asimismo, su aporte como profesora y concertista de piano es inestimable. Ha actuado en los más importantes escenarios del mundo al lado de grandes directores de orquesta, entre ellos Sergiu Celibidache, Hermann Scherchen, Stanislaw Skrowaczewski, Stanislaw Wislocki y Eugene Ormandy, en memorables presentaciones en escenarios, como el Carnegie Hall de Nueva York.

Por su lado, la maestra de piano Luisa Negri trabajó ininterrumpidamente treinta y cinco años en el Conservatorio Nacional de Música, ocupando los cargos de profesora principal de la especialidad de piano, siendo premiada en vida con las Palmas Magisteriales en el grado de Amauta, a nombre de la nación. 


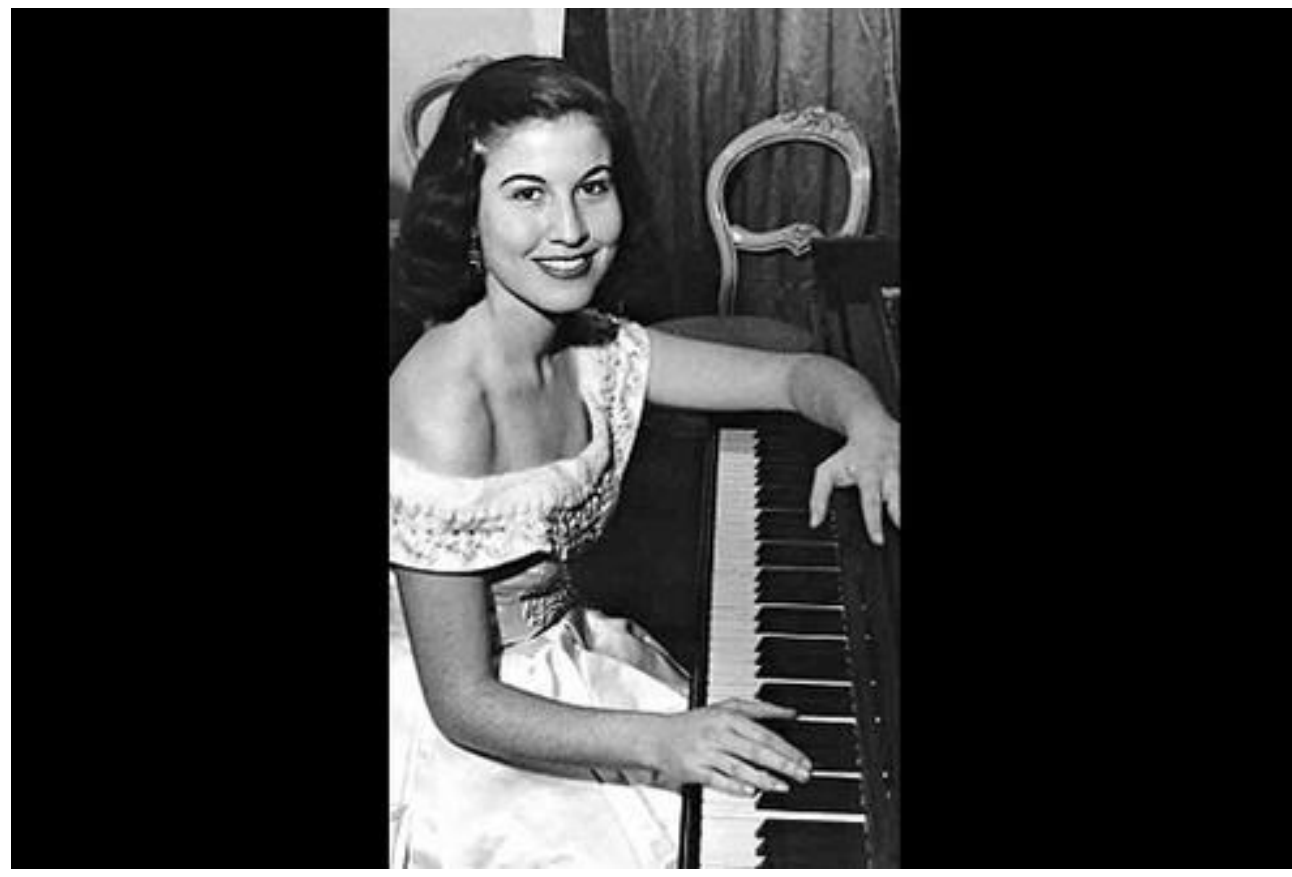

Figura N 3. Teresa Quesada. [fotografía] https://elcomercio.pe/luces/musica/teresaquesada-partida-maestra-musica-221032-noticia/

Otra solista de piano de gran nivel es Marcella Mazzini, quien reside actualmente en Chile y está dedicada a la docencia, habiendo sido nombrada en el año 2020 Profesora Emérita de la Universidad de Concepción. Ostenta distinciones como el Premio Municipal de Arte de la Municipalidad de Concepción (1993), el Premio Claudio Arrau de Artes Musicales del Gobierno Regional y el Premio Regional de Arte y Cultura, categoría Artes Musicales (2009).

De relevante trayectoria artística es la solista de piano Elsa Pulgar Vidal, quien ha ofrecido conciertos y recitales en diferentes países de Norte, Sud América y Europa, habiendo actuado bajo la batuta de maestros como Alejandro Koseleff, Olav Roots y otros. Ana Savaraín es, a su vez, clavecinista y profesora honoraria del Conservatorio Nacional de Música, siendo docente en la Universidad de Viena y agregada cultural en dicha ciudad.

Entre las solistas de piano destacadas están, Ana Toguchi, pianista y pintora, profesora del Conservatorio Nacional de Música; Luchy Gonzalez renombrada solista de piano y directora de coros; Liliana Cino, solista de piano y Embajadora del Perú. Liliana Cino ha representado al Perú tocando como solista en México, Brasil, USA, Suecia y Dinamarca; Carmen Escobedo, 
solista de piano de gran trayectoria artística, docente y académica, importante impulsora de la educación musical en el Perú habiendo sido Directora General del Conservatorio Nacional de Música y de la posterior Universidad Nacional de Música.

A este grupo de relevantes intérpretes se une Lidia Hung, pianista especializada en varios estilos como música de cámara renacentista y barroca, docente y ex directora del Conservatorio Nacional de Música; Pilar Zúñiga, destacada solista de piano y docente, discípula de Luisa Negri. Especialista en música barroca, de cámara y dirección coral, así como profesora de la Escuela de Música de la PUCP; Priscilla Navarro, solista de piano ganadora de varios concursos en USA y Europa; Mónica Cárdenas, pianista y compositora, merecedora de varios premios como el World music Award o Rosa Villar importante solista de piano peruana que reside en USA. Teresa Ornano de Costa ha participado activamente de la formación de pianistas destacados, influyendo de manera relevante en el quehacer musical nacional a través de sus críticas musicales en la página cultural del diario "El Comercio".

Entre algunas docentes que formaron a importantes pianistas y músicos en el Conservatorio Nacional de Música, podemos mencionar a Cucha Carreño, Elena Ichikawa, Elena Nosawa, Norma Sosa, Inés Spiers de De la Puente, Edelmy Chávez y Catia Palacios.

En la especialidad de canto, el Perú ha dado también grandes representantes, entre las que figuran Dora Brousset, formadora de renombrados cantantes; Betty Montoya, soprano, especialista en educación artística; Pilar Ciruelos, directora de la Escuela de Música de la Pontificia Universidad Católica del Perú o Nelly Suarez, contralto muy destacada y ex directora del Conservatorio Nacional de Música.

En el Perú también contamos con varias directoras de orquesta, de banda y de coro. Carmen Moral, es una de las más respetadas directoras de orquesta de Latinoamérica, siendo, a su vez la primera mujer directora de Latinoamérica. Es docente de dirección orquestal en la Berklee College of Music en Boston. Varias orquestas le han confiado el cargo de directora musical, como la Filarmónica de Bogotá (Colombia), Ia Frauen-Kammerorchester von Österreich (Viena), y la Orquesta Sinfónica de la Universidad Mimar Sinan (Estambul). Directora Emérita y Honoraria de la Orquesta Sinfónica Nacional del Perú. Ostenta un Doctorado Honoris Causa de la Universidad Femenina del Sagrado Corazón - UNIFE de Lima, habiendo sido invitada a dirigir varias orquestas de Latinoamérica, USA, Europa y Asia. Ha recibido varios premios y reconocimientos por su importante labor, siendo un ejemplo a seguir para las futuras generaciones de directoras mujeres. 


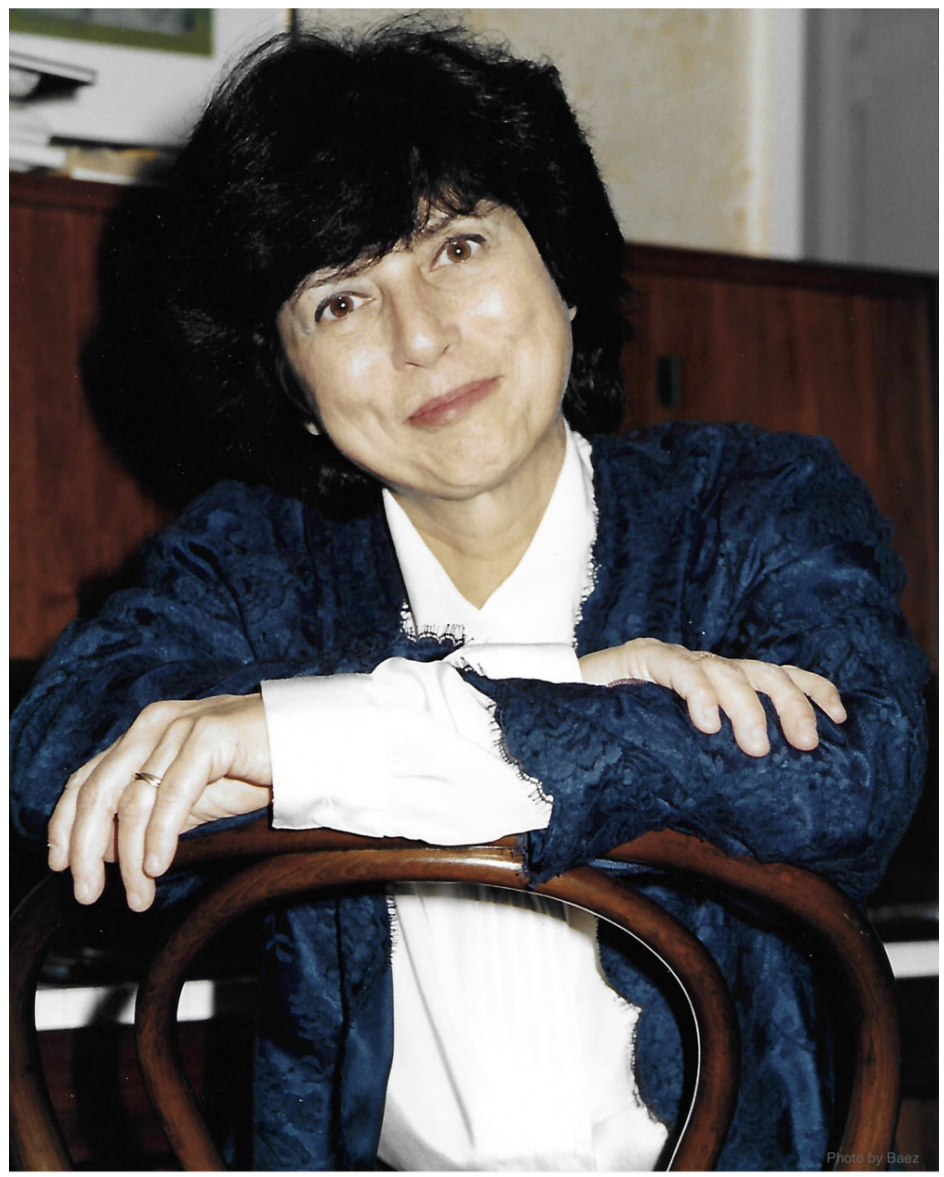

$N$ 4. Carmen Moral. Figura Tomada del archivo personal.

Nacida en Lima, Mina Maggiolo Dibos es Historiadora del Arte y Magíster en Historia de la UNMSM. Estudió en el Conservatorio Nacional de Música (hoy, Universidad Nacional de la Música), realizando una especialización de dirección de orquesta en la Accademia Chigianna en Sienna, Italia. Ha sido directora de la Orquesta Sinfónica Nacional del Perú entre los años 1996-2001 y directora Titular de la Orquesta Sinfónica Nacional del Perú entre los años 2006-2009. Es docente de la de la Facultad de Letras y Ciencias Humanas en la UNMSM, donde enseña cursos de su especialidad. Ha dirigido gran cantidad de conciertos a lo largo del país y del extranjero. Asimismo, ha sido directora invitada de la Orquesta Sinfónica Nacional de Brasil y de la Orquesta Sinfónica Municipal de Mar del Plata, en Argentina. Ha sido reconocida por su excelente labor tanto artística como didáctica en numerosas ocasiones. 


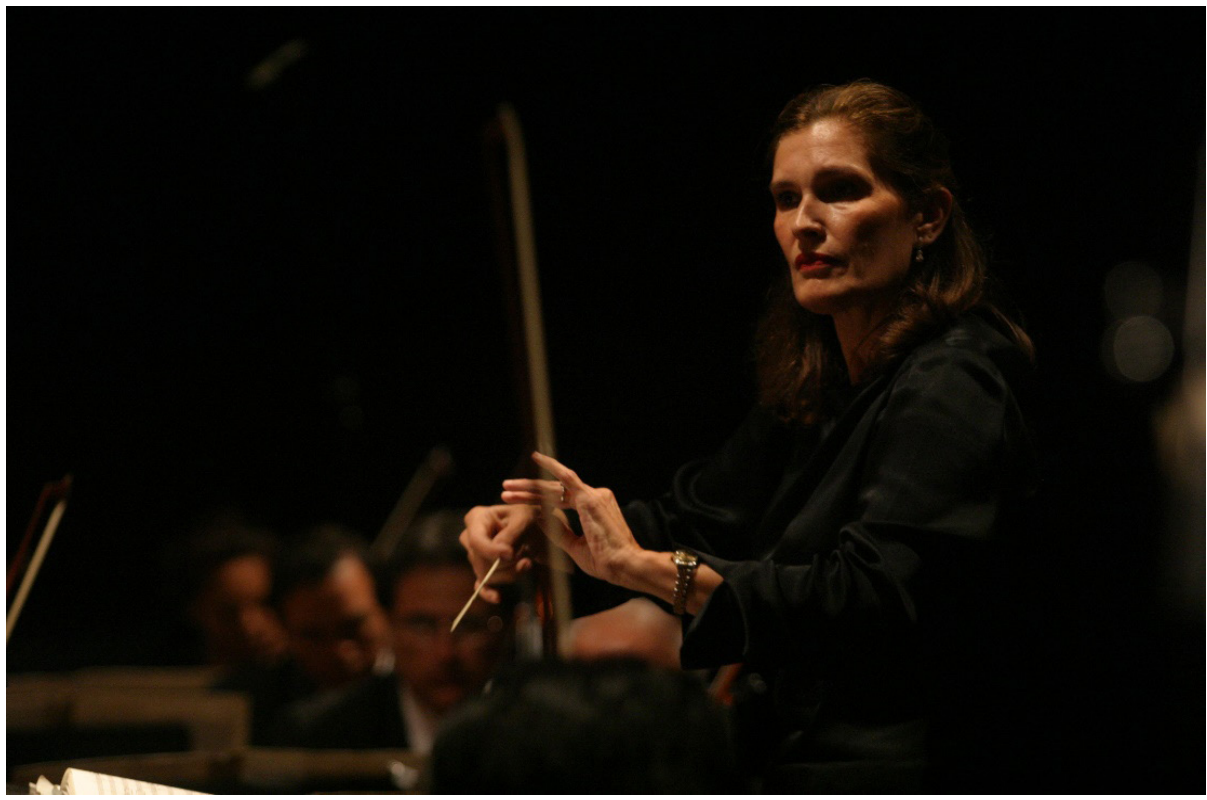

Figura N 5. Mina Maggiolo Dibos. Tomado del Archivo personal

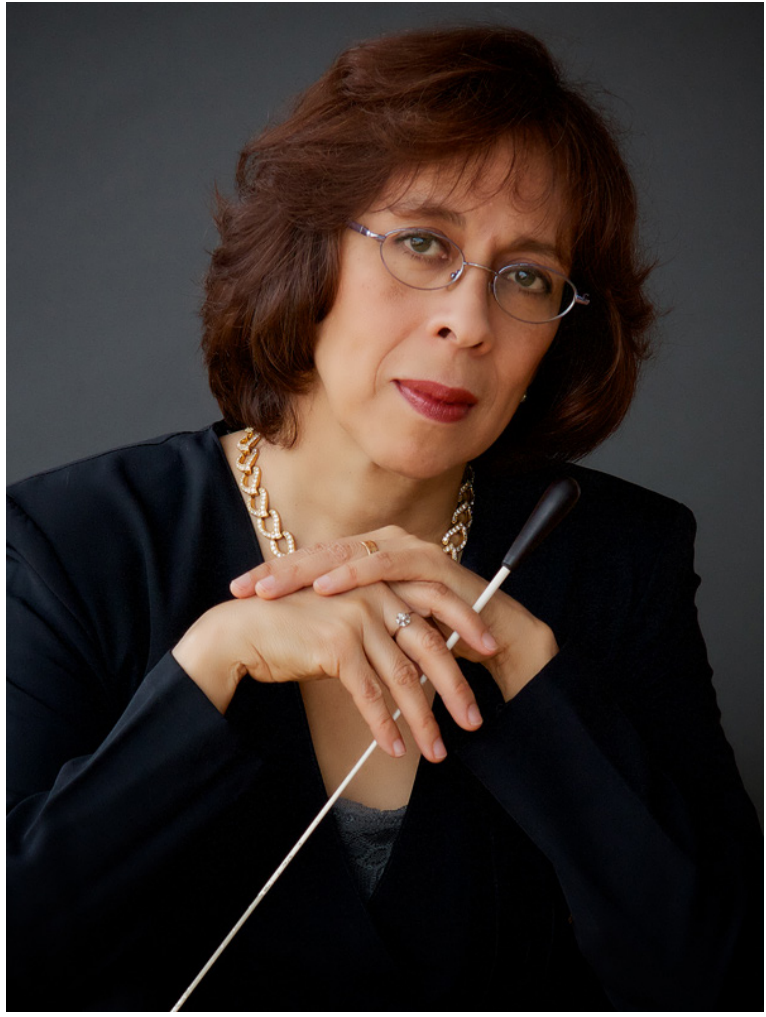

Figura N 6. Carlota Mestanza. Tomado del archivo personal. 
Por su lado, Carlota Mestanza es natural de Lima y estudió en el Perú, en Italia y Estados Unidos. Lleva 36 años de intensa actividad profesional en la música, tanto en el campo de la educación como en el de la dirección de orquesta, en el Perú y en el extranjero. Ha sido directora de la Orquesta Sinfónica de Trujillo en dos oportunidades, directora de la Orquesta Sinfónica de la Universidad Nacional de Música y ha dirigido numerosas orquestas en nuestro continente, en calidad de invitada. Vivió nueve años en Japón donde difundió de manera muy activa el repertorio de compositores peruanos. Como educadora, ha participado en numerosos festivales musicales en Japón, China, Corea del Sur y Vietnam. Su actividad le ha merecido numerosos reconocimientos y distinciones.

Una reconocida directora de orquesta, violinista, investigadora y docente es Zoila Vega Salvatierra. Licenciada en música de la Universidad Nacional San Agustín de Arequipa y Magister en Artes y mención en musicología en la Facultad de Artes de la Universidad de Chile. Realizó una destacada labor como directora titular de la Orquesta Sinfónica de Arequipa. Es docente de la Universidad San Agustín y de la maestría de la Escuela de Música de la Pontificia Universidad Católica del Perú.

De la misma manera, Lila Arroyo es fundadora y directora artística de la Orquesta Filarmónica Infantil del Perú.

También tenemos directoras peruanas de bandas de jazz, como Carolina Aráoz, fundadora de la banda "jazz-on".

Por otro lado, Mónica Gastelumendi es, además de directora de coros, coordinadora de la especialidad de música en la Facultad de Artes escénicas de la Pontificia Universidad Católica del Perú; Claudia Reineck, fundadora y directora del coro de niños "Voces del Sol" y, finalmente, Mónica Canales es directora del Coro Nacional de niños del Perú.

En otros campos de la música nacional, destacan, a su vez Angélica Cáceres de Arce, cellista, profesora emérita del Conservatorio Nacional de Música; Virginia Yep solista de guitarra e investigadora, Magíster y Doctora en Musicología comparada de la Freie Universität en Alemania. María Elena Pacheco es violinista, solista de violín, ex concertino de la Orquesta Sinfónica Nacional del Perú, con estudios en La Hochschule für Musik Detmold, Alemania y discípula del gran violinista Lukas David. De gran versatilidad, María Elena Pacheco se desempeña en diversos estilos musicales, llevando la música nacional a innumerables auditorios de varios países e importantes escenarios. 
En Arequipa, destacan Alejandra Lopera, flautista y Pilar Lopera pianista quienes realizan una permanente labor musical de gran nivel, continuando con la tradición musical arequipeña. María Eugenia Codina desempeña una interesante labor como intérprete de guitarra y de cello y también de instrumentos antiguos de cuerda, como laúd y viola da gamba, conformando el conjunto de música antigua de la PUCP. Del mismo modo, Bárbara Bollinger se desempeña como intérprete de diversos instrumentos antiguos, como la viola da gamba e instrumentos de viento. Clara Petrozzi, nacida en el Perú y afincada en Finlandia, es una destacada musicóloga, compositora, violinista y violista.

Por otra parte, Matilde González ha desarrollado una notable labor docente en el Conservatorio Nacional de Música, formando fagotistas, que en la actualidad conforman las filas de las orquestas importantes de nuestro país. De la misma manera, Ana Barrera ha desempeñado un aporte relevante en la formación de clarinetistas, así como Martina Jara, quien ha realizado una destacada labor docente en el campo musical. Por su lado, Florencia Ruiz Rosas, distinguida flautista con estudios en Francia, es docente de flautistas en la Universidad Nacional de Música. La cellista de origen finlandés, radicada en el Perú, Anika Petrozzi, quien es docente de la Universidad Nacional de Música es una activa pedagoga formadora de cellistas, además de difusora en nuestro medio del método de enseñanza Suzuki, manteniendo una activa participación en conciertos.

En la Orquesta Sinfónica Nacional, Paloma Chávez desempeña el cargo de capo de flautas, con la personalidad y talento necesarios para desempeñar ese importante papel, además de haberse dedicado, con constancia, a la docencia. Otras damas peruanas que participan en la Orquesta Sinfónica Nacional, como violinistas, violistas, cellistas, cornistas, clarinetistas, fagotistas y arpistas, vienen desempeñando una gran labor profesional, llevando el nombre de nuestro primer elenco nacional a un elevado nivel.

Mención especial es la que debemos hacer de la maestra María Foust, de origen ruso, quien vive en el Perú hace veinte años, desarrollando una fructífera e ininterrupida labor como concertino de la Orquesta Sinfónica Nacional desde el año 2008. Al mismo tiempo, desarrolla la labor de docente de violín en la Universidad de la Música, donde imparte sus conocimientos desde hace quince años. A su vez, es creadora y directora artística del ensamble de cuerdas Camerata Paqari, conformada por mujeres solistas talentosas del ambiente musical limeño. La Camerata tiene el propósito de visibilizar la labor de la mujer en la sociedad. 
Además de las ya mencionadas, existen muchas otras mujeres destacadas en el campo musical del Perú, habiéndonos limitado a mencionar sólo a algunas de ellas, con el fin de tener una idea clara de la importancia que han tenido, durante estos años en el mundo musical, tanto local como internacional.

La mujer peruana sobresale en muchos ámbitos profesionales, confirmando así su dedicación al estudio y su sólida preparación. En el caso puntual de la música, siendo una expresión artística tan exigente, es de dominio público la dedicación que un intérprete debe de darle al estudio y a la práctica de su instrumento, como al adecuado conocimiento de las partituras en el caso de la dirección o de la composición musical.

El hecho de tener tan relevantes figuras como exponentes en las distintas manifestaciones musicales, sólo comprueba, una vez más, el talento, profesionalismo y dedicación tan característicos de la mujer peruana.

\section{CONCLUSIÓN}

Hemos tratado de explicar la naturaleza de la música y sus manifestaciones, en el hombre primitivo como un medio de comunicación y de imitación de su entorno natural para obtener sus necesidades. Posteriormente, tratamos de comprender el desarrollo intelectual y social del ser humano a través de la historia y, su relación con el arte musical. Para, descubrir de qué forma la mujer participa en las manifestaciones musicales públicas. Finalmente, hemos nombrado a algunas de las figuras femeninas destacadas de los siglos XX-XXI en el Perú.

\section{REFERENCIAS}

Arróspide de la Flor, C. (2000). Introducción al estudio de la Música. Ed. Pontificia Universidad Católica del Perú.

Fubini, E. (2005). La estética musical desde la Antigüedad hasta el siglo XX. Ed. Alianza Música.

Hauser, A. (1969). Historia Social de la Literaturay el Arte. Ediciones Guadarrama.

Bolaños, C. (1998). La Música en el Antiguo Perú. Ed. Patronato Popular y Porvenir Pro Música Clásica. pp 3-64.

Perrot, M. (2009). Mi historia de las mujeres. Ed. Fondo de Cultura Económica. 
Sachs, C. (1981). La Música en el mundo antiguo oriente y occidente. Sansori Editore.

Samuel, C. (2007). Clara Schumann. Secretos de una pasión. Editorial Ateneo.

Fecha de recepción : 10 de noviembre de 2021

Fecha de aceptación : 23 de noviembre de 2021 